\title{
BMJ Open Factor analyses of the Chinese Zarit Burden Interview among caregivers of patients with schizophrenia in a rural Chinese community
}

\author{
Bingwei Tang, ${ }^{1}$ Yu Yu, ${ }^{1,2}$ Ziwei Liu, ${ }^{1}$ Meijuan Lin, ${ }^{1}$ Yumei Chen, ${ }^{1}$ Mei Zhao, ${ }^{1}$ \\ Shuiyuan $\mathrm{Xiao}^{1}$
}

To cite: Tang B, Yu Y, Liu Z, et al. Factor analyses of the Chinese Zarit Burden Interview among caregivers of patients with schizophrenia in a rural Chinese community. BMJ Open 2017;7:e015621. doi:10.1136/ bmjopen-2016-015621

- Prepublication history for this paper is available online. To view these files, please visit the journal online (http://dx.doi org/10.1136/bmjopen-2017015621).

Received 20 December 2016 Revised 3 August 2017 Accepted 16 August 2017

\section{CrossMark}

${ }^{1}$ Department of Social Medicine and Health Management, Xiangya School of Public Health, Central South University, Changsha, China

${ }^{2}$ Hospital Evaluation Office, Xiangya Hospital Central South University, Changsha, China

Correspondence to

Dr Shuiyuan Xiao;

xiaosy@csu.edu.cn

\section{ABSTRACT}

Objective This study aimed to evaluate the factor structure of the Chinese version of the 22-item Zarit Burden Interview (ZBI) among family caregivers of patients with schizophrenia in China.

Methods Using one-stage cluster-sampling design, 324 primary caregivers of patients with schizophrenia in Ningxiang County, Hunan Province, China, completed the Zarit Burden Interview face-to-face. Confirmatory factor analysis (CFA) was first performed based on existing models to check model fit. Owing to an unsatisfactory result of CFA, exploratory factor analysis (EFA) was then conducted to explore a new factor structure, and a subsequent CFA was run to examine its model fit. Results The CFA results showed that none of the existing models fit the data reasonably well. The EFA results suggested five dimensions: negative emotion (10 items), interpersonal relationship (4 items), time demand (3 items), patient's dependence (2 items) and self-accusation and guilt (2 items). The following CFA confirmed the fivefactor solution in this study, and the goodness-of-fit for this model fell within the acceptable range. The overall internal consistency (Cronbach's alpha) was 0.88 , and the internal consistency coefficients of individual dimensions were 0.68 to 0.84 .

Conclusion This study supported a 22-item ZBI scale, with a five-factor structure when applied to Chinese caregivers of patients with schizophrenia.

\section{INTRODUCTION}

The burden on caregivers of patients with schizophrenia is an important and serious problem, having a physical, mental, social and financial impact on patients and caregivers. ${ }^{1-4}$ At least 200 different instruments have been developed to assess the burden on caregivers of patients with schizophrenia. ${ }^{5}$ The 22-item version of Zarit Burden Interview (ZBI) is one of the most widely used measures of caregiver burden, which assesses the impact of caregiving on caregivers including physical, mental, social and economic aspects. The 22 items are rated on a 5-point Likert-type scale, and item 22 is a global measure assessing
Strengths and limitations of this study

- This was the first factor analyses of the Zarit Burden Interview in a Chinese community sample of caregivers of patients with schizophrenia, using both confirmatory factor analysis and exploratory factor analysis.

The sample size was relatively small.

- The sample was from only one geographical area of Hunan Province in China, and generalisation of the findings should be done with caution with regard to caregivers in other regions.

general caregiving burden. Originally developed to assess burden on caregivers of patients with dementia, ${ }^{6-10}$ the ZBI has been widely used in measuring caregiver burden related to patients with schizophrenia, which also has demonstrated good reliability and validity. $^{11-13}$

Although the ZBI has been identified by its developer as a non-dimensional scale, some researchers have argued that caregiver burden is multidimensional and that an aggregate score cannot accurately reflect the burden experienced by caregivers. The most commonly reported factor structure of the ZBI consists of personal and role dimensions. ${ }^{14}$ There are also other suggested factor structures, including three to five factor models. ${ }^{15-22}$

Based on a review of the literature, we have found various factor structures of the ZBI in different studies, which seemed to be related to the cultural background of the samples and statistical techniques used. ${ }^{17}{ }^{19}$ Considering that factor analysis is sample dependent ${ }^{23}$ and that most factor structures suggested for the ZBI were based on studies outside of China, we aimed to conduct a factor analyses of the ZBI based on a sample of Chinese caregivers of patients with schizophrenia in a rural area. 
Toward this end, our plan was to first perform confirmatory factor analysis (CFA) to examine whether existing factor models fit the data of our Chinese sample. If none of the previous models were found to be ideal, we would conduct exploratory factor analysis (EFA) to explore a new factor structure, and then, the new factor structure would be further tested by CFA.

\section{METHOD}

\section{Sample size calculation}

The present study was part of a large project 'study on family burden and experiences of primary caregivers of schizophrenia in community', ${ }^{24}$ which had a sample size of 327. After deleting three invalid questionnaires owing to missing values, we had a sample size of 324 for the present study, which met the minimum requirement for factor analysis. ${ }^{25}$

\section{Participants}

The study was conducted in the rural areas of Ningxiang County, Hunan Province, using a one-stage cluster-sampling design. Inclusion criteria for caregiver selection were as follows: (1) caring for patients registered in China's National Continuing Management and Intervention Program for Psychoses, (2) caring for patients diagnosed with schizophrenia based on the Chinese Classification of Mental Disorders, Third Edition or International Classification of Diseases, Tenth Edition, (3) living with the patient, taking most of the responsibility of caring and fully understanding the situation of both the patient and the family and (4) being older than 16 years. Exclusion criteria included the following: (1) caring for patients having comorbidity with other diseases such as epilepsy and (2) being unable to understand the contents of the questionnaire. A total of 352 primary caregivers of patients with schizophrenia were eligible for the study and recruited through China's National Continuing Management and Intervention Program for Psychoses. Among the 352 caregivers, 14 refused to participate and 11 dropped out during interviews. Owing to missing data, 324 valid questionnaires were used for the analysis.

\section{Procedure}

The survey was conducted from November 2015 to January 2016. After signing an informed consent form, each participant was asked to complete a face-to-face interview. All participants received some gifts equivalent to 10 Yuan for their participation. The study was approved by the Human Research Ethic Committee of the Xiangya School of Public Health of Central South University.

\section{Measures}

Social demographic characteristics showed in table 1 were collected by a questionnaire designed for use in this study. The ZBI consists of 22 items, examining caregivers' concern for physical, mental, social and economical aspects of caregiving. Each item is assessed on a 5-point

\begin{tabular}{|c|c|}
\hline Variables & $\mathrm{n}(\%)$ or mean (SD) \\
\hline \multicolumn{2}{|l|}{ Gender, n (\%) } \\
\hline Male & $152(46.9)$ \\
\hline Female & $172(53.1)$ \\
\hline Age (years), mean (SD) & $57.8(12.9)$ \\
\hline \multicolumn{2}{|l|}{ Marriage, $n(\%)$} \\
\hline Married & $274(84.6)$ \\
\hline Single & $7(2.2)$ \\
\hline Widowed & $41(12.7)$ \\
\hline Divorced or separated & $2(0.6)$ \\
\hline \multicolumn{2}{|l|}{ Occupation, n (\%) } \\
\hline Full-time employed & $18(5.6)$ \\
\hline Half-time employed & $155(47.8)$ \\
\hline Housewife/house husband & $92(28.4)$ \\
\hline Retired & $26(8.0)$ \\
\hline Unemployed & 33 (10.2) \\
\hline \multicolumn{2}{|l|}{ Education, n (\%) } \\
\hline Primary & $183(56.5)$ \\
\hline Middle & $93(28.7)$ \\
\hline High & $48(14.8)$ \\
\hline \multicolumn{2}{|l|}{ Relation with the patient, $\mathrm{n}(\%)$} \\
\hline Spouse & $147(45.4)$ \\
\hline Parents & $96(29.6)$ \\
\hline Siblings & $28(8.6)$ \\
\hline Children & $22(6.8)$ \\
\hline Other relatives & $31(9.6)$ \\
\hline $\begin{array}{l}\text { Duration of coresidence (years), } \\
\text { mean (SD) }\end{array}$ & $30.01(13.55)$ \\
\hline \multicolumn{2}{|l|}{ Duration of coresidence (years), $\mathrm{n}(\%)$} \\
\hline$<10$ & $29(9.0)$ \\
\hline$\geq 10$ & $292(90.1)$ \\
\hline $\begin{array}{l}\text { Duration of caregiving (years), mean } \\
\text { (SD) }\end{array}$ & $16.54(10.92)$ \\
\hline \multicolumn{2}{|l|}{ Duration of caregiving (years), $\mathrm{n}(\%)$} \\
\hline$<10$ years & 89 (27.5) \\
\hline$\geq 10$ years & $229(70.7)$ \\
\hline \multicolumn{2}{|l|}{ Whether having cocaregivers, $\mathrm{n}(\%)$} \\
\hline No & $144(44.4)$ \\
\hline Yes & $180(55.6)$ \\
\hline
\end{tabular}

Likert scale, ranging from $0=$ ='never' to $4=$ ='nearly always,' with higher scores indicating greater burden. A total score is calculated by adding the response score for each item, with total scores ranging from 0 to 88 . The original ZBI considers a score in the range of $61-88$ as severe burden, $41-60$ as moderate to severe burden, 21-40 as mild to moderate burden and less than 21 as little or 
no burden. ${ }^{26}$ The ZBI has been translated into several languages. The Chinese version of the ZBI was translated by Lie Wang. ${ }^{27}$ Internal consistency reliability of the different language versions ranges from 0.82 to $0.93 .{ }^{28-32}$ Psychometric assessment of the Chinese version has been conducted with samples of caregivers of patients with dementia and caregivers of inpatients, respectively, ${ }^{21} 22$ but has not been conducted among caregivers of patients with schizophrenia.

\section{Statistical analysis}

Owing to the ZBI data violating the assumption of multivariate normality, we used the Satorra-Bentler procedure of robust maximum likelihood to correct the statistic (and fit indices based on it) and SE of parameter estimates in the context of CFA. First, we conducted CFA to examine existing models. ${ }^{14} 1618192122$ As X ${ }^{2}$ statistic is sensitive to sample size leading to the greater chance of making a type I error, we also reported the Goodness of Fit Index (GFI), Root Mean Square Error of Approximation (RMSEA), Comparative Fit Index (CFI) and Non-Normed Fit Index (NNFI) (TLI). The following cut-off criteria for the goodness of fit indices were used: CFI $>0.90$, GFI $>0.90$, NNFI $>0.90$ and RMSEA $<0.060 .1^{33}$ As the results of CFA did not support any of the preidentified models, we then conducted EFA to explore the underlying factor structure of the scale after removing item 22, because item 22 is a global measure of caregiving burden and has correlated highly with all other items. ${ }^{22}$ The Bartlett's test and the Kaiser-Meyer-Olkin (KMO) index were used to assess suitability of the data for factor analysis, followed by varimax rotation method. Items with factor loadings greater than 0.40 were considered to belong to a specific factor.

Internal consistency reliability was evaluated by calculating Cronbach's alpha, with a recommended level of 0.70 or above considered as satisfactory.

Statistical analysis was conducted using SPSS 18.0 and LISREL 8.7. The statistical significance level of this study was set at 0.05 .

\section{RESULTS}

\section{Participants' characteristics}

As showed in table 1, 172 (53.1\%) caregivers were women, and $152(46.9 \%)$ were men. Age of caregivers ranged from 16 to 87 years $(57.8 \pm 12.9)$. Most of the primary caregivers were married $(84.6 \%)$. The majority of respondents had an educational level of elementary school or below $(56.5 \%)$ and were employed part-time $(47.8 \%)$. Parents $(29.6 \%)$ and spouse $(45.4 \%)$ were the major caregivers. Most of the primary caregivers had been living with the patient for longer than 10 years $(90.1 \%)$ and caring for the patient for over 10 years $(70.7 \%)$.

\section{Factor analyses}

CFA showed that none of the existing models identified in previous literature (see table 2) fit the data reasonably well (see table 3). We then ran EFA to explore the factor structure of the ZBI scale with item 22 removed. KMO index was 0.87 , and the Bartlett's Test of Sphericity was $2686.764(\mathrm{p}<0.000)$, indicating adequate sampling and a suitable correlation matrix for the factor analysis. The EFA results revealed five factors (see table 4 ). One item (item 17) crossloaded on factor 1 and factor 2, but it conceptually fit with factor 1 . The first factor, accounting for $32.24 \%$ of the variance, was named negative emotion (items 4, 5, 7, 9, 10, 15, 16, 17, 18 and 19). Factor 2, accounting for $8.35 \%$ of the variance, was termed interpersonal relationship (items 6, 11, 12 and 13). Factor 3 (time demand), accounting for $8.10 \%$ of the variance, consisted of 3 items (items 1, 2 and 3). Factor 4, accounting for $6.76 \%$ of the variance, was regarded as patient's dependence (items 8 and 14). Factor 5 (self-accusation and guilt), accounting for $5.09 \%$ of the variance, included two items (items 20 and 21). We conducted CFA on the five-factor model with the 21 items, which showed a moderate fit to the data. Although the $\mathrm{X}^{2}$ statistic and the GFI index indicated that the model did not provide a good fit to the data, other indices fell within the acceptable range $\left(\chi^{2}=381.13\right.$, $\mathrm{p}<0.001, \mathrm{CFI}=0.97$; GFI $=0.89$; NNFI $=0.96$; RMSEA=0.059) (see table 3). The Cronbach's alpha of the final model was 0.88 . Internal consistency coefficients of individual subscales ranged from 0.68 to 0.84 .

\section{DISCUSSION}

To the best of our knowledge, this is the first factor analyses of the ZBI in a Chinese community sample of caregivers of patients with schizophrenia, using both CFA and EFA. Our results support a five-factor structure: negative emotion (items 4, 5, 7, 9, 10, 15, 16, 17, 18 and 19), interpersonal relationship (items 6, 11, 12 and 13), time demand (items 1, 2 and 3), patient's dependence (items 8 and 14) and self-accusation and guilt (items 20 and 21).

Existing studies have suggested that burden is a multidimensional construct, and a global score cannot provide a complete and accurate assessment. ${ }^{22}$ As none of the existing models was found to fit our data well, we have yielded a five-dimension structure through EFA. Although we identified more factors than what has been found in other populations, our factors were similar to those models proposed by Ko et al and Lu et al among Chinese caregivers of patients with dementia and caregivers of inpatients, respectively ${ }^{21}{ }^{22}$ but with different items selected. Differences across these studies may be related to differences in the composition of caregiver samples and techniques used, ${ }^{17}$ because providing care for patients with different types of diseases needs different levels of caregiving involvement. In addition, EFA is often considered as a relatively subjective statistical procedure, and different choice of data analysis methods and different criteria used to retain factors may result in different factor models. ${ }^{34}$ Further studies are needed to confirm the structure in a Chinese context, in light of the considerable differences in the distribution of items. 
Open Access

Table 2 Dimensions of the Zarit Burden Interview Index reported in the literature

\begin{tabular}{|c|c|c|c|c|}
\hline Study & Sample & Method & $\begin{array}{l}\text { Factor } \\
\text { numbers }\end{array}$ & Factor name and items \\
\hline \multirow[t]{2}{*}{ Whitlatch et $a 1^{14}$} & 113 dementias & EFA & 2 & Personal strain: $1,4,5,8,9,14,16,17,18,19,20$ and 21 \\
\hline & & & & Role strain: 2, 3, 6, 11, 12 and 13 \\
\hline \multirow[t]{2}{*}{ Hébert et $a^{32}$} & 312 dementias & & 2 & Personal strain: 9,17 and 18 \\
\hline & & & & Role strain: $2,3,6,7,10,11,12,13$ and 22 \\
\hline \multirow[t]{2}{*}{ Bédard et $a l^{40}$} & 413 dementias & EFA & 2 & Personal strain: 19, 20 and 21 \\
\hline & & & & Role strain: $2,3,5,6,9,10,11,12$ and 17 \\
\hline \multirow[t]{2}{*}{ O'Rourke et $a l^{41}$} & $\begin{array}{l}1095 \text { and } 770 \\
\text { dementias }\end{array}$ & $\begin{array}{l}\text { EFA and } \\
\text { CFA }\end{array}$ & 2 & Role strain: 19,20 and 21 \\
\hline & & & & Personal strain: $2,3,5,6,9,10,11,12$ and 17 \\
\hline \multirow[t]{2}{*}{ Bachner et al ${ }^{42}$} & $\begin{array}{l}148 \text { cognitive } \\
\text { impairment }\end{array}$ & EFA & 2 & Personal strain: 19, 20 and 21 \\
\hline & & & & Role strain: $2,3,5,6,9,10,11,12$ and 17 \\
\hline \multirow[t]{2}{*}{ Bachner et al/3 } & 96 cancer & EFA & 2 & Personal strain: 19, 20 and 21 \\
\hline & & & & Role strain: $2,3,5,6,9,10,11,12$ and 17 \\
\hline \multirow[t]{3}{*}{ Knight et al ${ }^{15}$} & $\begin{array}{l}220 \text { and } 108 \\
\text { dementias }\end{array}$ & $\begin{array}{l}\text { EFA and } \\
\text { CFA }\end{array}$ & 3 & Patient's dependency: 2, 8 and 14 \\
\hline & & & & Self-criticism: 20 and 21 \\
\hline & & & & Embarrassment/anger: $4,5,6,9,10,11,12,13$ and 18 \\
\hline \multirow[t]{3}{*}{ Ankri et $a 1^{16}$} & 152 dementias & EFA & 3 & Psychological burden: 4, 5, 9, 18, 19 and 22 \\
\hline & & & & Impact on caregiving: $1,6,11,12,13$ and 17 \\
\hline & & & & Guilt or self-criticism: 15, 16, 20 and 21 \\
\hline \multirow[t]{3}{*}{ Springate et $a l^{17}$} & 206 dementias & EFA & 3 & Impact on caregiver's life: $2,3,6,9,10,11,12,17,18$ and 22 \\
\hline & & & & Guilt: 5, 19, 20 and 21 \\
\hline & & & & Frustration/embarrassment: 1, 4, 13 and 14 \\
\hline \multirow[t]{4}{*}{ Cheng et $a l^{19}$} & $\begin{array}{l}183 \text { and } 212 \\
\text { Alzheimer }\end{array}$ & $\begin{array}{l}\text { EFA and } \\
\text { CFA }\end{array}$ & 4 & Personal strain: $1,2,3,4,6,7,8,9$ and 10 \\
\hline & & & & Captivity: $11,12,13$ and 14 \\
\hline & & & & Loss of control: 16,17 and 19 \\
\hline & & & & Self-criticism: 20 and 21 \\
\hline \multirow[t]{4}{*}{$\begin{array}{l}\text { Al- } \\
\text { Rawashdeh et al }{ }^{18}\end{array}$} & $\begin{array}{l}124 \text { heart } \\
\text { failure }\end{array}$ & EFA & 4 & Consequences of caregiving: $2,3,5,6,9,10,11,12,15$ and 17 \\
\hline & & & & Patient's dependence: 1,8 and 14 \\
\hline & & & & Exhaustion and uncertainty: 4, 13, 16, 18 and 19 \\
\hline & & & & Guilt and fear for patient's future: 7,20 and 21 \\
\hline \multirow[t]{5}{*}{ Ko et $a l^{21}$} & 181 dementias & EFA & 5 & Caregiver's oversacrifice: $2,3,10,15,16,17,18$ and 22 \\
\hline & & & & Patient's dependence: $8,11,12$ and 14 \\
\hline & & & & Negative emotion: 4, 5, 6, 9 and 13 \\
\hline & & & & Inadequacy: 20 and 21 \\
\hline & & & & Uncertainty about patient's future: 1,7 and 19 \\
\hline \multirow[t]{5}{*}{ Lu et $a l^{22}$} & 523 dementias & $\begin{array}{l}\text { EFA and } \\
\text { CFA }\end{array}$ & 5 & Sacrifice: $3,7,8,10,11,12,13$ and 14 \\
\hline & & & & Loss of control: $15,16,17$ and 19 \\
\hline & & & & Embarrassment/anger: 4, 5, 6 and 9 \\
\hline & & & & Self-criticism: 20 and 21 \\
\hline & & & & Dependence: 1,2 and 18 \\
\hline
\end{tabular}

CFA, confirmatory factor analysis; EFA, exploratory factor analysis. 


\begin{tabular}{|c|c|c|c|c|c|c|}
\hline Model description & $\chi^{2}$ & df & GFI & CFI & NNFI (TLI) & RMSEA \\
\hline Whitlatch -2 factors, 18 items & 634.39 & 134 & 0.80 & 0.88 & 0.87 & 0.11 \\
\hline Ankri-3 factors, 16 items & 348.43 & 87 & 0.86 & 0.92 & 0.90 & 0.096 \\
\hline Cheng -4 factors, 18 items & 644.92 & 129 & 0.82 & 0.90 & 0.89 & 0.10 \\
\hline Al-Rawashdeh -4 factors, 21 items & 792.90 & 183 & 0.79 & 0.90 & 0.88 & 0.10 \\
\hline Lu - 5 factors, 21 items & 693.18 & 179 & 0.81 & 0.92 & 0.90 & 0.094 \\
\hline Ko-5 factors, 22 items & 748.03 & 199 & 0.81 & 0.92 & 0.91 & 0.092 \\
\hline 5 factors, 22 items & 381.13 & 179 & 0.89 & 0.97 & 0.96 & 0.059 \\
\hline
\end{tabular}

CFI, Comparative Fit Index; GFI, Goodness of Fit Index; NNFI, Non-Normed Fit Index; RMSEA, Root Mean Square Error of Approximation.

Our largest factor was negative emotion. This dimension incorporates several factors referred to by other researchers as negative emotion, ${ }^{35}$ psychological burden ${ }^{16}$ and fear for patients' future. ${ }^{18}$ On examination of item

Table 4 Exploratory factor analyses for the 21-item Zarit Burden Interview

\begin{tabular}{|c|c|c|c|c|c|}
\hline \multirow[b]{2}{*}{ Item } & \multicolumn{5}{|c|}{5 dimension } \\
\hline & $\mathrm{F1}^{*}$ & F2† & F3¥ & F4§ & F5n \\
\hline 4 & 0.69 & & & & \\
\hline 5 & 0.68 & & & & \\
\hline 7 & 0.61 & & & & \\
\hline 9 & 0.60 & & & & \\
\hline 10 & 0.43 & & & & \\
\hline 15 & 0.61 & & & & \\
\hline 16 & 0.66 & & & & \\
\hline 17 & 0.52 & 0.43 & & & \\
\hline 18 & 0.55 & & & & \\
\hline 19 & 0.66 & & & & \\
\hline 6 & & 0.81 & & & \\
\hline 11 & & 0.61 & & & \\
\hline 12 & & 0.83 & & & \\
\hline 13 & & 0.72 & & & \\
\hline 1 & & & 0.62 & & \\
\hline 2 & & & 0.80 & & \\
\hline 3 & & & 0.70 & & \\
\hline 8 & & & & 0.86 & \\
\hline 14 & & & & 0.83 & \\
\hline 20 & & & & & 0.89 \\
\hline 21 & & & & & 0.89 \\
\hline Eigenvalue & 6.77 & 1.75 & 1.70 & 1.42 & 1.07 \\
\hline $\begin{array}{l}\text { Proportion of } \\
\text { explained variance } \\
\text { (\%) }\end{array}$ & 32.24 & 8.35 & 8.10 & 6.76 & 5.09 \\
\hline
\end{tabular}

${ }^{\star} \mathrm{F} 1=$ Negative emotion.

$\dagger F 2=$ Interpersonal relationship.

‡F3=Time demand.

§F4=Patient's dependence.

१F5=Self-accusation and guilt. content, we have found that this factor encompasses several complicated feelings of caregivers in caring for the patient, including anger, concern, annoyance, anxiety, frustration and embarrassment; therefore, we named it negative emotion.

Our second largest factor was interpersonal relationship, which is labelled as interpersonal relation, ${ }^{36}$ embarrassment/anger ${ }^{15}$ or captivity ${ }^{19}$ in other studies. In this study, we have named it interpersonal relationship, because all of these items describe the impact of caring for patients with schizophrenia on caregiver's social life.

The third largest factor was time demand comprising three items (items 1, 2 and 3), which belong to specific factors in different studies. In this study, we have termed this factor time demand owing to the fact that caregiving leads to caregivers' time insufficiency or restrictions on caregivers' time, which bears resemblance to the time-dependence burden factor reported by Novak and Guest ${ }^{37}$

The fourth factor was patient's dependence, which is also found in other Asian samples, ${ }^{21}{ }^{38}$ indicating the patient's dependence on the caregiver.

The last factor was self-accusation and guilt comprising only two items (items 20 and 21). Although there were differences in the samples, this factor was also found in the Chinese context ${ }^{192122}$ as well as several other cultural contexts and appears to be the most stable or generalisable factor across samples and cultures. ${ }^{15} 39$

Several limitations of this study should be noted. First, we did not evaluate the caregiver's depressive and anxious symptoms for providing evidence of construct validity in the present study. Second, the sample size was relatively small; therefore, it would also strengthen the results if the EFA results we have reported here can be tested by CFA among a different sample of caregivers of patients with schizophrenia. In addition, the findings reflect only one geographical area of Hunan Province in China. As such, generalisation of the findings should be done with caution with regard to caregivers in other regions. Further research is needed to overcome these limitations.

Notwithstanding these limitations, our study of ZBI adds to the understanding of dimensions of caregiver burden in a rural Chinese community. Results from this study support a 22-item ZBI scale, with a five-factor structure when applied to Chinese caregivers of patients with 
schizophrenia. In future studies, CFA of the five-factor structure should be conducted with other populations and disorders.

Acknowledgements The authors thank all of the families of the patients with schizophrenia we interviewed during the study for openly sharing their feelings and experiences. We also thank the health and family planning bureau of Ningxiang County and the governments of Liushahe Town, Shungfupu Town, Chengjiao Xiang and Yutan Town for their administrative support, as well as all village/community doctors for guiding us to visit each household of the patients with schizophrenia in the rural areas of Ningxiang County, Hunan Province, China.

Contributors SX contributed to the study conceptualisation, acquisition and administration. BT led the study design, data analyses and writing of the paper. YY contributed to the study conceptualisation, data collection and writing of the paper. ZL, ML, YC and MZ interpreted the data, revised the article and edited the manuscript. Xiguang Liu, Xiaochuan Chen and Xingyu Zhang contributed to the data collection and data analyses.

Funding This study was funded by 'CMB-CSU' Collaborative Program for Mental Health Policy Development (II) (grant no CMB 14-188).

Competing interests None declared.

Patient consent Obtained.

Ethics approval The Xiangya School of Public Health of Central South University.

Provenance and peer review Not commissioned; internally peer reviewed.

Data sharing statement № additional unpublished data are available.

Open Access This is an Open Access article distributed in accordance with the Creative Commons Attribution Non Commercial (CC BY-NC 4.0) license, which permits others to distribute, remix, adapt, build upon this work non-commercially, and license their derivative works on different terms, provided the original work is properly cited and the use is non-commercial. See: http://creativecommons.org/ licenses/by-nc/4.0/

(c) Article author(s) (or their employer(s) unless otherwise stated in the text of the article) 2017. All rights reserved. No commercial use is permitted unless otherwise expressly granted.

\section{REFERENCES}

1. Caqueo-Urízar A, Miranda-Castillo C, Lemos Giráldez S, et al. An updated review on burden on caregivers of schizophrenia patients. Psicothema 2014;26:235-43.

2. Rafiyah I. Review: burden on family caregivers caring for patients with schizophrenia and its related factors. Nurse Media J Nursing 2011:1:29-41.

3. Chien WT, Chan SW, Morrissey J. The perceived burden among Chinese family caregivers of people with schizophrenia. J Clin Nurs 2007;16:1151-61.

4. Chan SW. Global perspective of burden of family caregivers for persons with schizophrenia. Arch Psychiatr Nurs 2011;25:339-49.

5. Harvey K, Catty J, Langman A, et al. A review of instruments developed to measure outcomes for carers of people with mental health problems. Acta Psychiatr Scand 2008;117:164-76.

6. Wang G, Cheng Q, Wang Y, et al. The metric properties of zarit caregiver burden scale: validation study of a Chinese version. Alzheimer Dis Assoc Disord 2008;22:321-6.

7. Braun M, Scholz U, Hornung R, et al. [Caregiver burden with dementia patients. A validation study of the German language version of the zarit burden interview]. $Z$ Gerontol Geriatr 2010;43:111-9.

8. Hirono N, Kobayashi H, Mori E. [Caregiver burden in dementia: evaluation with a Japanese version of the zarit caregiver burden interview]. No To Shinkei 1998;50:561-7.

9. Majerovitz SD. Role of family adaptability in the psychological adjustment of spouse caregivers to patients with dementia. Psychol Aging 1995;10:447-57.

10. Zarit SH, Orr NK, Zarit JM. Understanding the stress of caregivers: planning an intervention. In: The hidden victims of Alzheimer's disease: Families under stress. New York: New York University Press, 1985:69-86.

11. Hanzawa S, Tanaka G, Inadomi H, et al. Burden and coping strategies in mothers of patients with schizophrenia in Japan. Psychiatry Clin Neurosci 2008;62:256-63.
12. Yusuf AJ, Nuhu FT. Factors associated with emotional distress among caregivers of patients with schizophrenia in Katsina, Nigeria. Soc Psychiatry Psychiatr Epidemiol 2011;46:11-16.

13. Caqueo-Urízar A, Gutiérrez-Maldonado J, Ferrer-García M, et al. Typology of schizophrenic symptoms and quality of life in patients and their main caregivers in northern Chile. Int J Soc Psychiatry 2013;59:93-100.

14. Whitlatch CJ, Zarit SH, von Eye A. Efficacy of interventions with caregivers: a reanalysis. Gerontologist 1991;31:9-14.

15. Knight BG, Fox LS, Chou C-P. Factor structure of the burden interview. J Clin Geropsychol 2000;6:249-58.

16. Ankri J, Andrieu S, Beaufils B, et al. Beyond the global score of the zarit burden interview: useful dimensions for clinicians. Int J Geriatr Psychiatry 2005;20:254-60.

17. Springate BA, Tremont G. Dimensions of caregiver burden in dementia: impact of demographic, mood, and care recipient variables. Am J Geriatr Psychiatry 2014;22:294-300.

18. Al-Rawashdeh SY, Lennie TA, Chung ML. Psychometrics of the zarit burden interview in caregivers of patients with heart failure. $J$ Cardiovasc Nurs 2016;31:E21-8.

19. Cheng ST, Kwok T, Lam LC. Dimensionality of burden in Alzheimer caregivers: confirmatory factor analysis and correlates of the zarit burden interview. Int Psychogeriatr 2014:1-9.

20. Chien WT, Norman I. The validity and reliability of a Chinese version of the family burden interview schedule. Nurs Res 2004;53:314-22.

21. Ko KT, Yip PK, Liu SI, et al. Chinese version of the zarit caregiver burden interview: a validation study. Am J Geriatr Psychiatry 2008;16:513-8.

22. Lu L, Wang L, Yang X, et al. Zarit caregiver burden interview: development, reliability and validity of the Chinese version. Psychiatry Clin Neurosci 2009;63:730-4.

23. Furr RM, Bacharach VR. Psychometrics: an introduction. 2nd edn. London: Sage Publication, 2014.

24. Yu Y.Study on family burden and expereiences of primary caregivers of schizophrenia in community, 2015.

25. Laurence G. Grimm Paul R. Yarnold. Reading and Understanding More Multivariate Statistics. 1st edn. Washington, American Psychological Association, 2000.

26. Dwl L. Validation of the zarit burden interview for Chinese Canadian caregivers. Soc Work Res 2007;31:45-53.

27. Lie W, Xiaoshi Y, Zhe H, et al. Application and evaluation of Chinese version of zarit caregiver burden interview. Chin J Public Health 2006;22:970-2.

28. Ozer N, Yurttaş A, Akyil RÇ. Psychometric evaluation of the Turkish version of the zarit burden interview in family caregivers of inpatients in medical and surgical clinics. J Transcult Nurs 2012;23:65-71.

29. Flynn Longmire CV, Knight BG. Confirmatory factor analysis of a brief version of the zarit burden interview in black and white dementia caregivers. Gerontologist 2011;51:453-62.

30. Siegert RJ, Jackson DM, Tennant A, et al. Factor analysis and rasch analysis of the zarit burden interview for acquired brain injury carer research. J Rehabil Med 2010;42:302-9.

31. Higginson IJ, Gao W. Caregiver assessment of patients with advanced cancer: concordance with patients, effect of burden and positivity. Health Qual Life Outcomes 2008;6:42.

32. Hébert R, Bravo G, Préville M. Reliability, validity and reference values of the zarit burden interview for assessing informal caregivers of community-dwelling older persons with dementia. Can J Aging 2000;19:494-507.

33 Wu ML. Structural equation modeling. China: Chongqing University Press, 2010.

34 Norris M, Lecavalier L. Evaluating the use of exploratory factor analysis in developmental disability psychological research. $J$ Autism Dev Disord 2010;40:8-20.

35 Tang JY, Ho AH, Luo H, et al. Validating a cantonese short version of the zarit burden interview (CZBI-Short) for dementia caregivers. Aging Ment Health 2016;20:996-1001.

36 Galindo-Vazquez O, Benjet C, Cruz-Nieto MH, et al. Psychometric properties of the zarit burden interview in Mexican caregivers of cancer patients. Psychooncology 2015;24:612-5.

37 Novak M, Guest C. Application of a multidimensional caregiver burden inventory. Gerontologist 1989;29:798-803.

38 Matsushita M, Pai MC, Jhou CY, et al. Cross-cultural study of caregiver burden for Alzheimer's disease in Japan and Taiwan: result from Dementia Research in Kumamoto and Tainan (DeReKaT). Int Psychogeriatr 2016;28:1125-32.

39 Cheah WK, Han HC, Chong MS, et al. Multidimensionality of the zarit burden interview across the severity spectrum of cognitive impairment: an Asian perspective. Int Psychogeriatr 2012;24:1846-54. 
40 Bédard M, Molloy DW, Squire L, et al. The zarit burden interview: a new short version and screening version. Gerontologist 2001;41:652-7.

41 O'Rourke N, Tuokko HA. Psychometric properties of an abridged version of the zarit burden interview within a representative Canadian caregiver sample. Gerontologist 2003;43:121-7.
42 Bachner YG, Ayalon L. Initial examination of the psychometric properties of the short Hebrew version of the zarit burden interview. Aging Ment Health 2010;14:725-30.

43 Bachner YG. Preliminary assessment of the psychometric properties of the abridged Arabic version of the zarit burden interview among caregivers of cancer patients. Eur J Oncol Nurs 2013;17:657-60. 